\title{
Photo-bactericidal Properties of Hydroxyapatite Implant Surface Coating
}

\section{Maklygina Yu S ${ }^{1}$, Sharova AS ${ }^{2 *}$, Kundu B ${ }^{3}$, Balla VK ${ }^{3}$, Steiner $\mathbf{R}^{4}$ and Loschenov VB ${ }^{1,2}$}

${ }^{1}$ A.M. Prokhorov General Physics Institute, RAS, Russia, Moscow

${ }^{2}$ National Research Nuclear University, MEPhl, Russia, Moscow

${ }^{3}$ Bioceramics and Coating Division, CSIR-Central Glass and Ceramic Research Institute, Kolkata, India

${ }^{4}$ The Institute for Laser Technology in Medicine and Measurement Technique, UIm, Germany

\begin{abstract}
Implant-associated infection is a common postoperative complication and remains a serious problem in the surgery. This work describes the development of hydroxyapatite implants with photo-bactericidal properties by the surface coating. The unique coating as crystalline nanoparticles of IR photosensitizers of implant was investigated using infrared spectroscopy. It has been proved that by the interaction of nanoparticles covering implant with the polar solvent, which simulates the interaction of the implant with the biocomponents in vivo (fast proliferating and with immune-competent cells), IR photosensitizers nanoparticles change the spectroscopic properties, becoming fluorescent and phototoxic.

Thus, the developed coating based on crystalline IR photosensitizer nanoparticles with studied specific properties should have antibacterial, anti-inflammatory effect by the photodynamic treatment in the near implant area. This research opens the prospect of such technology application in order to provide the local inflammatory and autoimmune reactions prevention in the area of implantation that will improve implant antimicrobial effects and reduce potential long-term cytotoxicity. The results of the study suggest a promising this technology in order to create implants with photo-bactericidal properties.
\end{abstract}

Keywords: Aluminum; Phthalocyanine; Bacteriochlorin; Hydroxyapatite implants; Nano-photosensitizers; Photoluminescence; Photobactericidal effect of photodynamic therapy

\section{Introduction}

The research of the organic compounds and synthetic materials integration processes in biological tissue is crucial for improving the quality of life of patients in need of regeneration or replacement of tissue defects [1-6]. Implant techniques have found application in many areas of medicine (orthopedics, neurosurgery, cardiac surgery, dentistry, traumatology, etc.). Surgical intervention with subsequent implantation is a difficult process in terms of post-operative recovery, preventing inflammatory responses and of the implant rejection processes. During implantation, the immune system stimulates inflammatory and reparative response of the conjunctive tissue leading to the implant rejection [7-17]. This circumstance prevents implant biointegration and entails comorbidities.

At present the most perspective material, which is widely used in the field of clinical implantation, is hydroxyapatite (HAp). HAp is characterized by high stability, bioactivity and biocompatibility [18-23]. HAp was studied due to its crystallographical and chemical resemblance with the mineral part of the human hard tissue. It was proven that HAp has the ability to bond directly with bone tissue. Bacterial infections are associated with implant materials that may induce the local inflammation around the implant and eventually implant loss. This phenomenon is of major concern for both patients and health care providers because of the negative impact on patient quality of life and the economic cost of frequent implant replacements. Accordingly, there is a growing demand to inhibit bacterial colonization on implanted devices through the immobilization of an antibacterial agent on their surface that can both discourage initial bacterial adhesion and serve to kill them upon contact [24]. Porous bioactive ceramic such as HAp is one of the alternatives to be used as local drug delivery system. Furthermore, the inclusion of antimicrobial agents within HAp is expected to prevent or cure implant-associated infections via their direct release to local regions such as the implant-tissue interface. Antibiotics can also be applied on the implant surfaces [25] as photobactericidal substances, however, concerns exist regarding their efficacy considering the growing problem of antibiotic resistant bacteria and their short-term effect [26]. Thus, the leading developments are aimed at the implant design with antiseptic and bactericidal properties that will allow reducing of the immune processes duration and inflammatory reactions in biological tissues, ensuring the most comfortable conditions for implant biointegration [27-32].

Currently the most promising methods to achieve the bactericidal effect are physical methods particularly antimicrobial photodynamic therapy [33-38]. This method shows a pronounced photo bactericidal activity, anti-inflammatory effect and has gained more attention owing to its broad-spectrum antibacterial properties at very low concentrations, good biocompatibility, satisfactory safety profile, and inherent stability. Antimicrobial photodynamic therapy also prevents the dystrophic and sclerotic processes that can effectively reduce the risk of implant rejection and accelerate biointegration.

The photosensitizers (PS) seem the most promising as photobactericidal substances. The most interesting are the PS, which in contact with the implant surface do not lose their bactericidal properties and have enough grips with the HAp surface to prevent it from washing away by biointeraction. So the PS in nanoform are the

*Corresponding authors: Sharova AS, National Research Nuclear University, MEPhl, Russia, Moscow, Tel: +7 495 788-56-99; E-mail: us.samsonova@physics.msu.ru

Received July 19, 2016; Accepted July 27, 2016; Published August 05, 2016

Citation: Maklygina YS, Sharova AS, Kundu B, Balla VK, Steiner R, et al. (2016) Photo-bactericidal Properties of Hydroxyapatite Implant Surface Coating. Bioceram Dev Appl 6: 094. doi: 10.4172/2090-5025.1000094

Copyright: (c) 2016 Maklygina YS, et al. This is an open-access article distributed under the terms of the Creative Commons Attribution License, which permits unrestricted use, distribution, and reproduction in any medium, provided the original author and source are credited. 
most effective substances which do not exhibit their photodynamic activity in the absence of inflammatory agents (microbes, some immune cells) and become phototoxic and photoactive in contact with specific biocomponents [39,40]. The activity level of nanoparticles is evaluated by the intensity of the photoluminescence signal. This photoluminescence signal arises by interaction nanoparticles with inflammatory agents and may be detected as a monitoring and control study modes.

Bactericidal and anti-inflammatory effects of photoactive implants are associated with specific properties of photosensitizer nanoparticles by the laser radiation. HAp implants are of small sizes but have a large surface area due to its porous structure. Large surface area of the deposited PS nanoparticles layer directly comes into contact (interacts) with the biological tissue in vivo. The porous structure is well scatters excited photoluminescence radiation, which contributes to the effective nanoparticles activation over the implant surface and the extensive photodynamic effects.

\section{Materials and Methods}

Meso-tetra (3-pyridyl) bacteriochlorin and non-sulfonated phthalocyanine PcAl aluminum were used as PS which can provide the greatest penetration depth of photodynamic treatment. Test compounds have the absorption peak in the near infrared range corresponded to the region of maximum optical transparency of biological tissues. Optical properties of test compounds give reason to consider them as the most promising PS especially regard to monitoring of pathological processes with deep localization [41-44].

\section{Nanoparticles of bacteriochlorin ( $\mathrm{nBch}$ ) and Aluminum phthalocyanine (nPcAl)}

Meso-tetra(3-pyridyl)bacteriochlorin (hereinafter referred to as "bacteriochlorin") produced by the Organic Intermediates and Dyes Institute (Russia) (Figure 1a). Coarse crystals of aluminum phthalocyanine produced by the Organic Intermediates and Dyes Institute (Russia) (Figure 1b).

The aqueous colloid of molecular $\mathrm{nBch}$ and $\mathrm{nPcAl}$ were prepared as follows. For both samples, polycrystalline powder was added into the distilled water to obtain a concentration of $1 \mathrm{mg} / \mathrm{ml}$. The resulting suspension was dispersed in ultrasonic homogenizer Bandelin SONOPLUS HD2070 with nozzle KE76 $(20 \mathrm{kHz}, 165 \mu$ m amplitude).

By means of multi-angle dynamic light scattering spectrometer Photocor Complex (Russia), allowing to obtain the nanoparticle size distribution through analysis of correlation function of the dispersed light intensity fluctuations, it was determined that mean particle diameter in the aqueous colloid is $220 \div 240 \mathrm{~nm}$. It is important to note that the resulting $\mathrm{nBch}$ and $\mathrm{nPcAl}$ colloids not luminesce by laser excitation with 532 and $632.8 \mathrm{~nm}$ wavelengths, respectively. Thus, free forms of the PS nanocrystals show no photoactivity.
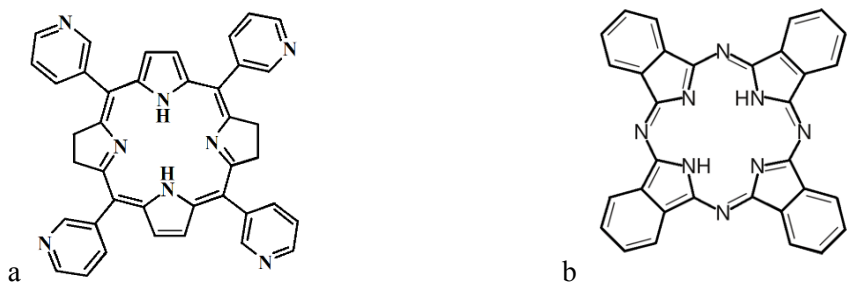

Figure 1: The chemical formula of the a) meso-tetra(3-pyridyl)bacteriochlorin molecule $b$ ) aluminum phthalocyanine molecule.
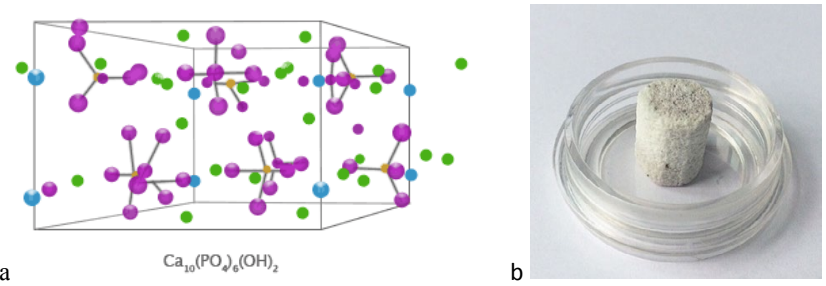

Figure 2: a) Crystalline hydroxyapatite packaging with the chemical formula $\mathrm{Ca}_{10}\left(\mathrm{PO}_{4}\right)_{6}(\mathrm{OH})_{2} ;$ b) Digital photo of hydroxyapatite implant.

\section{Hydroxyapatite (HAp)}

Coralline derived HAp is the most perspective biomaterial for implantation. HAp implants were synthesized by the research group of Professor Balla Vamsi Krishna in India. [45].

The tailor-made HAp implants were fabricated from the HAp powder. The HAp powder was prepared by precipitation between $\mathrm{Ca}(\mathrm{OH})_{2}$ and $\mathrm{H}_{3} \mathrm{PO}_{4}$ according to the following reaction:

$$
10 \mathrm{Ca}(\mathrm{OH})_{2}+6 \mathrm{H}_{3} \mathrm{PO}_{4}=\mathrm{Ca}_{10}\left(\mathrm{PO}_{4}\right)_{6}(\mathrm{OH})_{2}+18 \mathrm{H}_{2} \mathrm{O} \text {. }
$$

An aqueous solution of $\mathrm{H}_{3} \mathrm{PO}_{4}$ was added very slowly to a suspension of $\mathrm{Ca}(\mathrm{OH})$. During reaction, temperature of the suspension was maintained at $80^{\circ} \mathrm{C}$. The resulting precipitate was aged, dried and calcined at $800^{\circ} \mathrm{C}$. The calcined powder was ground in a planetary mill (Figure 2).

During the fabrication, the powder was intimately mixed with appropriate quantity of naphthalene powder by repeated sieving. The powder mix was inserted into rubber bag and compacted at a pressure of $160 \mathrm{MPa}$ by cold-isostatic pressing (EPSI NV; SO 10036, Belgium) to form cylindrical shape. By heating at $80^{\circ} \mathrm{C}$, the naphthalene was driven off from the green implant and great care was taken at this stage to prevent cracking. Finally, the implant was sintered at $1250^{\circ} \mathrm{C}$ for $3 \mathrm{~h}$ to improve the mechanical properties.

To achieve the photobactericidal effect in the area of implantation, the photosensitizers in nanoform were applied on the HAp implant surface. Porous implant surface was coated with relevant nanoparticles by incubation $(\mathrm{t}=30 \mathrm{~min})$ of the implant in a colloidal solution of $\mathrm{nBch}$ and nPcAl. Porous HAp structure allows nanoparticles to penetrate deep inside as evidenced by the color change in the implant thickness due to the characteristic color of colloidal photosensitizer solutions.

Spectroscopic properties of the nanoparticles were examined with the use of a fiber spectrometer LESA-01 "BIOSPEC" (in the range of 0.4 $\div 1.1 \mu \mathrm{m}$ ) in various conditions including the interaction with surface molecules of HAp [46]

\section{Results and Discussion}

Series of repeated and then averaged manipulation were carried out to study the dynamics of photosensitizer accumulation in the HAp porous structure. Implant biointegration process was simulated in the in vitro conditions as follows:

- Stage 1: The study examined the spectral properties of fluorescent nanoparticles by interaction with surface molecules of HAp, provided that free nanocrystals in aqueous colloid can't exhibit the luminescence;

- Stage 2: The study examined the spectral-luminescence properties of the coated implant in the interacting implant surface (HAp with the surface layer of nanoparticles) with a polar solvent (dimethyl sulfoxide - DMSO), which mimicked the interaction with biocomponents (immunocompetent cells, bacteria, etc. in vivo); 


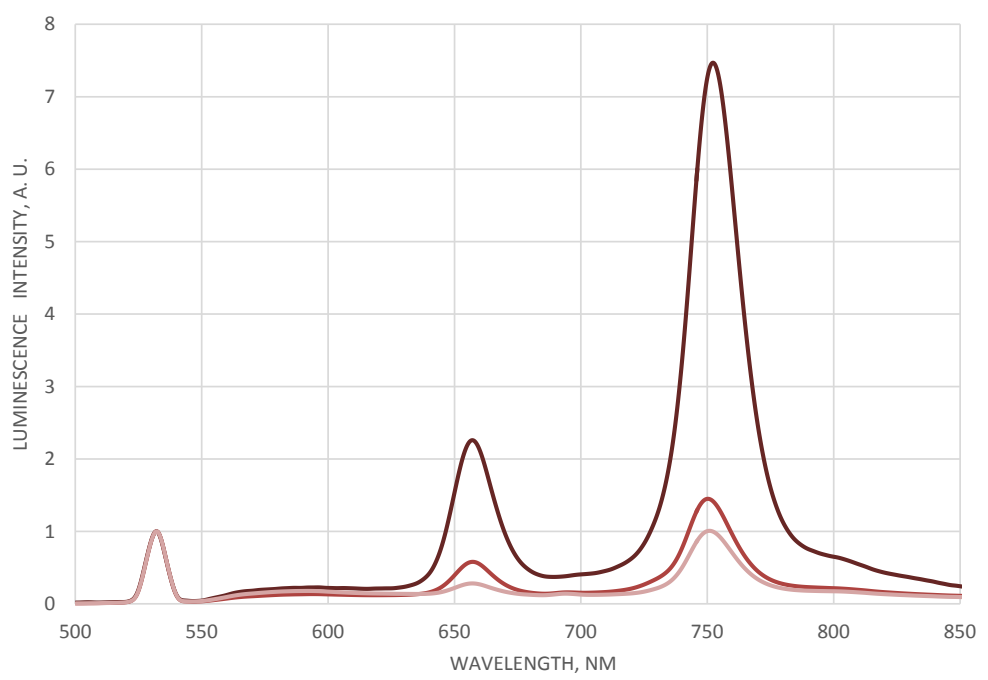

Figure 3: The luminescence spectrum of the HAp implant coated by nBch under the different conditions $\left(\lambda_{\mathrm{ex}}=532 \mathrm{~nm}\right)$ coated by nBch after exposure to the polar solvent DMSO, 2 implant coated by nBch after washout of a polar solvent.

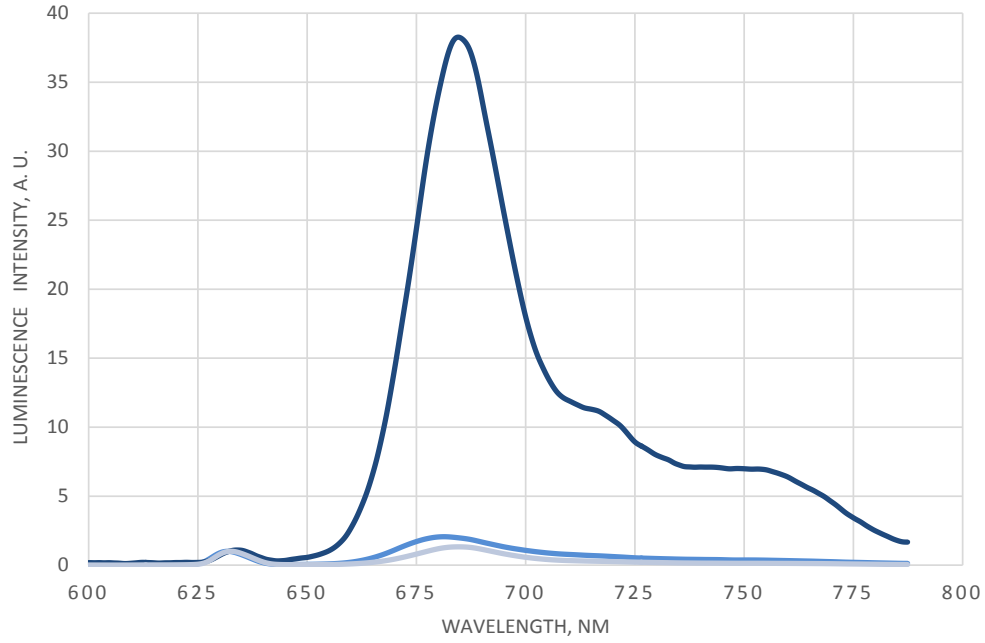

Figure 4: The luminescence spectrum of the HAp implant coated by nPcAl under the different conditions $\left(\lambda_{\mathrm{ex}}=632.8 \mathrm{~nm}\right):-$ implant coated by $\mathrm{nPcAl}$ implant coated by $\mathrm{nPcAl}$ after exposure to the polar solvent DMSO, implant coated by $\mathrm{nPcAl}$ after washout of a polar solvent.

- Stage 3: The study examined the spectral luminescence properties of the coated implant after polar solvent washing by aqueous dispersion in an ultrasonic homogenizer to avoid the possibility of decontamination of the nanoparticle surface layer under the action of biocomponents (in vivo).

Results of the stepwise exposure on the implant surface are presented in the form of luminescence spectra in Figures 3 and 4 for samples with a surface coating of $\mathrm{nBch}$ and $\mathrm{nPcAl}$, respectively.

Analysis of the luminescence spectra dynamics at various conditions for both types of crystalline nanoparticles (bacteriochlorin and aluminum phthalocyanine) shows that initially inphotoactivity PS nanocrystals by the interaction with HAp surface molecules change their spectroscopic properties and acquire the ability to luminesce. Probably this phenomenon can be explained by the interaction between the surface molecules of nanoparticles and complex surface structure of HAp. Surface molecules of nanocrystals may «lie» relative to the surface of the nanoparticle (taking parallel position) or may "wake up" relative to the surface of the nanoparticle (taking orthogonal position). Hence, the surface molecules show spectroscopic properties of PS solution (with the use of DMSO) depending on their location and position.

Thus, the process of photosensitizer crystalline nanoparticles activation is confirmed by a steep increase of the photoluminescence signal intensity (Figures 3 and 4) with the use of polar solvent, which permite to simulate the biocomponents interaction with the implant coated with the surface layer of PS nanoparticles in vivo.

During the study it was also found that the surface molecules of PS nanoparticles interact with the surface structure of HAp sufficiently strong, whereas the nanocrystals washout from the porous structure of the implant was not achieved by the way of aqueous dispersion. This fact is confirmed by the presence of the luminescence signal for both nanoparticle types after 3 stages of exposure (Figures 3 and 4).

Moreover, the luminescence spectra' dynamics of HAp -based implants surface coated with PS nanoparticles were experimentally investigated in the study. 


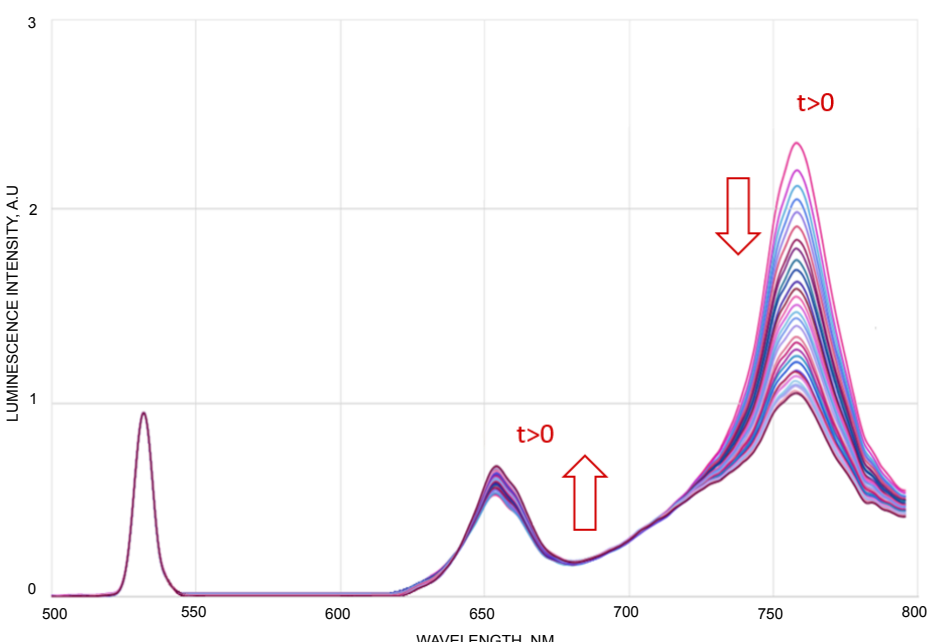

Figure 5: The dynamics of the luminescence spectrum time transforming of the implant based on hydroxyapatite coated by $\mathrm{nBch}\left(\lambda_{\mathrm{ex}}=532 \mathrm{~nm}\right)$.

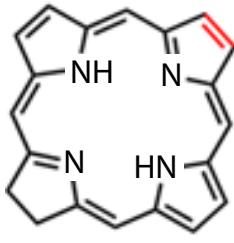

Chlorin

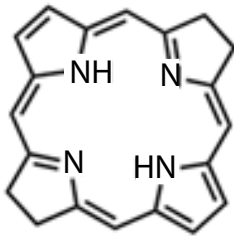

Bacteriochlorin
Figure 6: The chemical formula of chlorin and bacteriochlorin molecules.

The analysis of the luminescence spectra dynamics for both types of crystalline nanoparticles ( $\mathrm{nBch}$ and $\mathrm{nPcAl}$ ) shows that initially nonphotoactive PS nanocrystals acquire the ability to luminescence in contact with HAp surface molecules, though the intensity of luminescence peak varies with time under the influence of the exciting laser radiation ( $\mathrm{nBch}: \lambda_{\mathrm{ex}}=532 \mathrm{~nm}, \mathrm{nPcAl}: \lambda_{\mathrm{ex}}=632.8 \mathrm{~nm}$ ).

\section{Bacteriochlorin nanoparticles (nBch)}

The luminescence spectrum of the implant surface coated by $\mathrm{nBch}$ excited by laser radiation $\lambda_{\mathrm{ex}}=532 \mathrm{~nm}$ has two luminescence peaks $\lambda_{\mathrm{em}}=758 \mathrm{~nm}$ and $\lambda_{\mathrm{em}}=654 \mathrm{~nm}$. At constant exposure to the excitation laser radiation, the luminescence intensity peak changes over time. The intensity of the luminescence peak corresponding $\lambda_{\mathrm{em}}=654 \mathrm{~nm}$ increases over time, whereas the intensity of the luminescence peak corresponding $\lambda_{\mathrm{em}}=758 \mathrm{~nm}$ decreases over time (Figure 5). Apparently depending on the exposure time surface molecules change their position relative to each other and the surface structure of HAp, showing spectroscopic properties of bacteriochlorin solution $\left(\lambda_{\mathrm{em}}=\right.$ $758 \mathrm{~nm})$ or chlorin $\left(\lambda_{\mathrm{em}}=654 \mathrm{~nm}\right)$.

It should be noted that the process is reversible therefore structural change of the PS molecule or self-formation of chlorin molecules are impossible. Figure 6 shows that the difference in structure of bacteriochlorin and chlorin molecules is the presence of one more double bond in the chlorin compound. So the interaction between two neighbor molecules of bacteriochlorin may occur under the influence of the exciting laser light. This interaction is probably based on the formation between two molecules of common temporary double bond, which collapses in the absence of the exciting radiation.
In this instance, one of bacteriochlorin molecules may show chlorin spectroscopic properties. Thus, the $\mathrm{nBch}$ interact both pairs between themselves and with the complex porous structure of HAp. Depending both on the strength of interaction and own nanoparticle localization environment, PS molecules can take different positions relative to each other and the HAp surface. Variation of the PS molecule position leads to the spectroscopic properties changes but not at the expense of the molecular structure changes.

\section{Aluminum phthalocyanine nanoparticles (nPcAl)}

The luminescence spectrum of the implant surface coated by $\mathrm{nPcAl}$ has a luminescence peak $\lambda_{\mathrm{em}}=682 \mathrm{~nm}$ excited by laser radiation $\lambda_{\mathrm{ex}}=$ $632.8 \mathrm{~nm}$.

At constant exposure to the excitation laser radiation, the peak intensity of luminescence changes over time namely the intensity of the luminescence peak decreases over time (Figure 7). Apparently, depending on the exposure time surface molecules change their position relative to each other and the surface structure of HAp, leading to spectroscopic properties changes.

It should be noted that the process is reversible therefore structural change of the PS molecule or dye burnout are impossible.

Thus, the interaction of the nanoparticles with surface structure of the implant takes place through the surface molecules. In its turn, the surface molecules may take a different position with respect to the surface structure of HAp. Therefore, the surface covered with PS nanoparticles changes spectroscopic properties depending on the interaction forces, location and environment of the surface PS molecules, but not because of molecular structure changes.

\section{Conclusion}

Thus, the research has proved possibility to activate the nanoparticles covered the implant surface. Activity level of nanoparticles was estimated by the control of photoluminescence intensity. There was also found the strong interaction between the surface molecules of PS nanocrystals and HAp surface structure providing a strong grip.

The analysis of the luminescence spectra dynamics for the both types of crystalline nanoparticles showed that initially in photoactive PS nanocrystals acquire the ability to luminescence by reaction with 
Citation: Maklygina YS, Sharova AS, Kundu B, Balla VK, Steiner R, et al. (2016) Photo-bactericidal Properties of Hydroxyapatite Implant Surface Coating. Bioceram Dev Appl 6: 094. doi: 10.4172/2090-5025.1000094

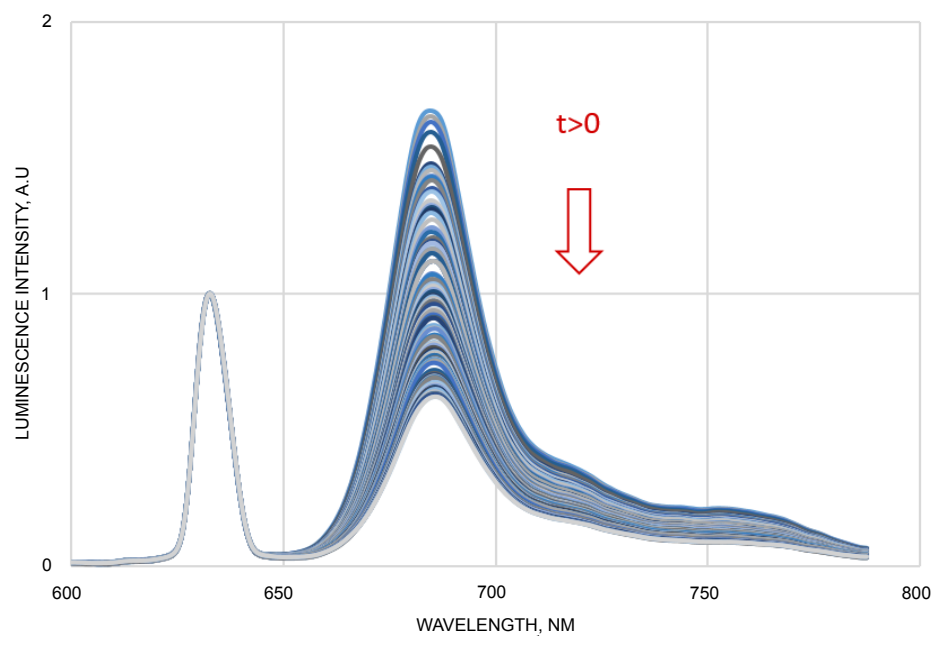

Figure 7: The dynamics of the luminescence spectrum time transforming of the implant based on hydroxyapatite coated by $\mathrm{nPcAl}\left(\lambda_{\mathrm{ex}}=632.8 \mathrm{~nm}\right)$.

HAp surface molecules. But the luminescence intensity varies over time under the influence of the exciting laser radiation. Based on this research it was concluded that the PS nanoparticles interact both among themselves and with a complex porous structure of the implant. Depending both on the interaction strength and own nanoparticle environment localization, PS molecules can take different positions relative to each other and the HAp surface. Variation of the PS molecule position leads to changing of the spectroscopic properties but not at the expense of the molecular structure changes. The findings of the study suggest this technology promising in order to create implants with photo-bactericidal properties.

\section{References}

1. Amini AR, Laurencin CT, Nukavarapu SP (2012) Bone tissue engineering: recent advances and challenges Crit Rev Biomed Eng. 40: 363-408.

2. Noh YK, Du P, Kim IG, Ko J, Kim SW, et al. (2016) Polymer mesh scaffold combined with cell-derived ECM for osteogenesis of human mesenchymal stem cells. Biomater Res 20: 6

3. Legemate K, Tarafedr S, Jun Y, Lee CH (2016) Engineering Human TMJ Discs with Protein-Releasing 3D-Printed Scaffolds. J Dent Res 95: 800-807.

4. Padmanabhan SK, Gervaso F, Carrozzo M, Scalera F, Sannino A, et al. (2013) Hydroxyapatite scaffolds with improved mechanical, bioactive and biodegradable properties for bone tissue engineering. Ceram Int 39:619-627.

5. Hosseinkhani M, Mehrabani D, Karimfar MH, Bakhtiyari S, Manafi A, et al (2014) Tissue engineered scaffolds in regenerative medicine. World J Plast Surg 3: 3-7.

6. Tevlin R, McArdle A, Atashroo D, Walmsley G, Senarath-Yapa G, et al (2014) Biomaterials for craniofacial bone engineering. J Dent Res 93: 1187-1195.

7. Galili U (2015) Avoiding detrimental human immune response against Mammalian extracellular matrix implants. Tissue Eng Part B Rev 21: 231-241.

8. Kharraz Y, Guerra J, Mann CJ, Serrano AL, Munoz-Canoves P (2013) Macrophage plasticity and the role of inflammation in skeletal muscle repair. Mediators Inflamm 2013: 491-497.

9. Brown BN, Sicari BM, Badylak SF (2014) Rethinking regenerative medicine: a macrophage-centered approach. Front Immunol 5: 510

10. Boehler RM, Graham JG, Shea LD (2011) Tissue engineering tools for modulation of the immune response. Biotechniques 51: 239-244.

11. Gardner AB, Lee SK, Woods EC, Acharya AP (2013) Biomaterials-based modulation of the immune system. Biomed Res Int 2013: 1-7.

12. Franz S, Rammelt S, Scharnweber D, Simon JC (2011) Immune responses to implants-a review of the implications for the design of immunomodulatory biomaterials. Biomaterials 32: 6692-6709.
13. Anderson JM (1988) Inflammatory response to implants. ASAIO Trans. 34: 101-107.

14. Major MR, Wong VW, Nelson ER, Longaker MT, Gurtner GC (2015) The foreign body response: at the interface of surgery and bioengineering. Plast Reconstr Surg 135: 1489-1498.

15. Londono R, Badylak SF (2014) Biologic scaffolds for regenerative medicine: mechanisms of in vivo remodeling. Ann Biomed Eng 43: 577-592.

16. Crupi AN, Costa A, Tarnok A, Melzer S, Teodori L (2015) Inflammation in tissue engineering: The Janus between engraftment and rejection. Eur J Immunol 45 3222-3236.

17. Kzhyshkowska J, Gudima A, Riabov V, Dollinger C, Lavalle P, et al. (2015) Macrophage responses to implants: prospects for personalized medicine. J Leukoc Biol 98: 953-962.

18. Van Oirschot BA, Eman RM, Habibovic P, Leeuwenburgh SC, Tahmaseb $Z$, et al. (2016) Osteophilic properties of bone implant surface modifications in a cassette model on a decorticated goat spinal transverse process. Acta Biomater.37: 195-205.

19. Nakata H, Kuroda S, Tachikawa N, Okada E, Akatsuka M, et al. (2016) Histological and micro-computed tomographic observations after maxillary sinus augmentation with poroushydroxyapatite alloplasts: a clinical case series Springerplus 5:260.

20. Pallela R, Venkatesan J, Janapala VR, Kim SK (2012) Biophysicochemica evaluation of chitosan-hydroxyapatite-marine sponge collagen composite for bone tissue engineering. J Biomed Mater Res Part A. 100A: 486-495

21. Asaoka T, Ohtake S, Furukawa KS, Tamura A, Ushida T.J (2013 Nov) Development of bioactive porous $\alpha-T C P / H A p$ beads for bone tissue engineering. Biomed Mater Res A 101: 3295-300.

22. Nandi SK, Kundu B, Mukherjee J, Mahato A, Datta S, et al. (2015) Converted marine coral hydroxyapatite implants with growth factors: in vivo bone regeneration. Mater Sci Eng C Mater Biol Appl 49: 816-823.

23. Balla VK, Bodhak S, Bose S, Bandyopadhyay A (2010 Aug) Porous tantalum structures for bone implants: fabrication, mechanical and in vitro biological properties. Acta Biomater 6: 3349-3359

24. Saenz de VV, Barandika G, Bayon R, Fernandez X, Ciarsolo I, et al. (2015) Development of Ti-C-N coatings with improved tribological behavior and antibacterial properties. J mech behave biomedi mat 55: 75-86.

25. Tian B, Tang S, Wang CD, Wang WG, Wu CL, et al. (2014) Bactericida properties and biocompatibility of a gentamicin-loaded Fe3O4/carbonated hydroxyapatite coating. Colloids surf B Biointerfaces 123: 403-412.

26. Fielding GA, Roy M, Bandyopadhyay A, Bose S (2012) Antibacterial and biological characteristics of silver containing and strontium doped plasma sprayed hydroxyapatite coatings. Acta biomaterialia 8: 3144-3352.

27. Ferraz MP, Mateus AY, Sousa JC, Monteiro FJ (2007) Nanohydroxyapatite 
Citation: Maklygina YS, Sharova AS, Kundu B, Balla VK, Steiner R, et al. (2016) Photo-bactericidal Properties of Hydroxyapatite Implant Surface Coating. Bioceram Dev Appl 6: 094. doi: 10.4172/2090-5025.1000094

microspheres as delivery system for antibiotics: release kinetics, antimicrobial activity, and interaction with osteoblasts. J Biomed Mater Res A 81: 994-1004.

28. Guo YJ, Long T, Chen W, Ning CQ, Zhu ZA, et al. (2013) Bactericida property and biocompatibility of gentamicin-loaded mesoporous carbonated hydroxyapatite microspheres. Mater Sci Eng C 33: 3583-3591.

29. Selvakumar M, Srivastava P, Pawar HS, Francis NK, Das B, et al. (2016) OnDemand Guided Bone Regeneration with Microbial Protection of Ornamented SPU Scaffold with Bismuth-Doped Single Crystalline Hydroxyapatite: Augmentation and Cartilage Formation. ACS Appl Mater Interfaces. 8: 40864100 .

30. Krishnan AG, Jayaram L, Biswas R, Nair M (2015) Evaluation of antibacterial activity and cytocompatibility of ciprofloxacin loaded gelatinhydroxyapatite scaffoldsas a local drug delivery system for osteomyelitis treatment. Tissue Eng Part A. 21: 1422-1431.

31. Mututuvari TM, Harkins AL, Tran CD Facile synthesis, characterization and antimicrobial activity of cellulose-chitosan-hydroxyapatitecomposite material: a potential material for bone tissue engineering

32. Afzal MA, Kalmodia S, Kesarwani P, Basu B, Balani K (2012) Bactericidal effect of silver-reinforced carbon nanotube and hydroxyapatite composites. J Biomed Mater Res A. 101: 3266-3277.

33. Haag PA, Steiger-Ronay V, Schmidlin PR (2015) The in Vitro Antimicrobial Efficacy of PDT against eriodontopathogenic Bacteria. Int J Mol Sci 16: 27327-27338.

34. Soukos NS, Ximenez-Fyvie LA, Hamblin MR, Socransky SS, Hasan T (1998) Targeted antimicrobial photochemotherapy. Antimicrob Agents Chemother 42 : 2595-2601.

35. WM, Allen CM, van Lier JE (1999) Photodynamic therapeutics: Basic principles and clinical applications. Drug Discov Today 4: 507-517.

36. Braham P, Herron C, Street C, Darveau R (2009) Antimicrobial photodynamic therapy may promote periodontal healing through multiple mechanisms. J Periodontol 80: 1790-1798.
37. Chan Y, Lai CH (2003) Bactericidal effects of different laser wavelengths on periodontopathic germs in photodynamic therapy. Lasers Med Sci 18: 51-55

38. Street CN, Pedigo LA, Loebel NG (2010) Energy dose parameters affect antimicrobial photodynamic therapy-mediated eradication of periopathogenic biofilm and planktonic cultures. Photomed Laser Surg 28: S61-S66.

39. Breymayer J, Rück A, Ryabova AV, Loschenov VB, Steiner RW (2014) Fluorescence Investigation of the Effect of Monocytes/Macrophages and Skin Cells on Aluminium Phthalocyanine Nanoparticles. J Photodiag PhotodynaTher 11: 380-390.

40. Vasilchenko SYu, Volkova Al, Ryabova AV, Loschenov VB, Konov VI, et al (2010) Application of aluminum phthalocyanine nanoparticles for fluorescent diagnostics in dentistry and skin autotransplantology. J Biophoton 3: 336-346.

41. Ryabova A, Steiner R, Loschenov V (2014) The crystalline nanoparticles from photosensitizers capable to metamorphose in biotissue. International Conference on Laser Applications in Life Sciences LALS. UIm, Germany.

42. Oertel M, Schastak, SI, Tannapfel A, Hermann R, Sack U, et al. (2003) Nove bacteriochlorin for high tissue-penetration: photodynamic properties in human biliary tract cancer cells in vitro and in a mouse tumour model. J Photochem Photobiol B. 71: 1 -10.

43. Mazor O, Brandis A, Plaks V, Neumark E, Rosenbach-Belkin V (2005) A nove water-soluble bacteriochlorophyll derivative; cellular uptake, pharmacokinetics, biodistribution, and vascular targeted photodynamic activity against melanoma tumors. Photochem Photobiol 81: 342-351.

44. Rovers JP, de Jode ML, Rezzoug H, Grahn MF (2000) In vivo photodynamic characteristics of the near-infrared photosensitizer 5,10,15, 20-tetrakis (m-hydroxyphenyl)bacteriochlorin. Photochem Photobiol 72: 358-364.

45. Kundu B, Sinha MK, Mitra MK, Basu D (2004) Fabrication and characterization of porous hydroxyapatite ocular implant followed by an in vivo study in dogs. Bull Mater Sci 27: 133-140.

46. Loschenov VB, Konov VI, Prokhorov AM (2000) Photodynamic therapy and fluorescence diagnostics. Laser Physics. 10: 1188-1207.
Citation: Maklygina YS, Sharova AS, Kundu B, Balla VK, Steiner R, et al. (2016) Photo-bactericidal Properties of Hydroxyapatite Implant Surface Coating. Bioceram Dev Appl 6: 094. doi: 10.4172/2090-5025.1000094 